\title{
Fabrication of Nanofiltration Membrane based on Polyvinyl Alcohol Nanofibers Reinforced with Cellulose Nanocrystal using Electrospinning Techniques
}

\author{
Heru SB Rochardjo ${ }^{*}$, Fatkhurrohman ${ }^{1}$, Ahmad Kusumaatmaja ${ }^{2}$, Ferriawan Yudhanto ${ }^{1,3}$ \\ ${ }^{1}$ Department of Mechanical and Industrial Engineering, Universitas Gadjah Mada, Jl. Grafika No. 2, \\ Yogyakarta 55281, Indonesia \\ ${ }^{2}$ Department of Physics, Universitas Gadjah Mada, Sekip Utara, Bulaksumur, Yogyakarta 55281, Indonesia \\ ${ }^{3}$ Department of Mechanical Engineering, Universitas Muhammadiyah Yogyakarta, Yogyakarta 55183, \\ Indonesia
}

\begin{abstract}
Filtration is an effective method in any process concerning the removal of potential infective substances via a size separation mechanism. The filter can be made from various materials. This research analyzes the fabrication of nanofiltration membranes made from polyvinyl alcohol (PVA) nanofibers reinforced with ramie cellulose nanocrystal (CNC) using the electrospinning method. The physical and mechanical properties of the filters were investigated with varying CNC concentrations in PVA to investigate the effect of the CNC content. The results showed that the fiber diameter in the membranes was not significantly related to the CNC content. However, the strength and elongation increased with an increase in CNC concentration until a certain value was reached, at which point it started decreasing. The SEM image showed that the membrane nanofibers have a pore size small enough to be used in a nanofiltration process. SEM-EDX and TGA/DSC testing were also carried out to determine the elements in the membrane and show the suitability of the thermal resistance.
\end{abstract}

Keywords: Cellulose nanocrystal; Electrospinning; Nanofiber membrane; Polyvinyl alcohol

\section{Introduction}

The Covid-19 virus is currently a global pandemic, with the first outbreak identified in Wuhan, China, in 2019. Since then, the virus has spread around the world. Therefore, it is essential to take the right steps to break the chain of its transmission. One of the strategies for preventing its transmission includes creating a nanofiber filter with smaller pores than the virus. This is because nanofibers show prospective filtration due to their controlled fiber diameter, high specific strength, high surface area, and mat pore size (Sanders et al., 2019).

The nanofiber is a fiber nano-sized in diameter. It can be produced from various types of polymers, including polyvinyl alcohol (PVA). Reinforcements for these polymers are valuable for strengthening their properties. The use of cellulose nanocrystal (CNC) as a reinforcement in the nanofiber membrane is supportive due to its nano dimensions, high aspect ratio, high crystallinity, low density, high mechanical strength, unique morphology, 
addition to these benefits, CNCs also have better properties than other fibers, including glass, steel wire, Kevlar, and graphite (Kim et al., 2015).

This study utilized cellulose from ramie fiber, which is a natural fiber containing $76 \%$ cellulose, $17 \%$ hemicellulose, and 1\% lignin (Heinze et al., 2018). However, studies on the use of ramie fibers as CNCs are scarcely found. The utilization is limited to handicrafts and fabrics despite its abundance in Indonesia due to its ability to grow adequately in any tropical region with good productivity. Cellulose can also be extracted from many other natural materials besides ramie fiber. For example, Helmiyati and Anggraini (2019) successfully researched the production of cellulose from rice husks.

Polyvinyl alcohol is a low-cost, water-soluble, biocompatible polymer used in many biomedical applications (Sousa et al., 2015). For these reasons, the combination of ramie CNC and PVA is expected to produce an excellent composite material with a higher strength in the nanofiber membrane.

In this study, a ramie CNC-filled PVA nanofiber membrane was manufactured using an electrospinning method. This technique is widely used for the production of membrane nanofibers despite the potential use of other methods, such as sol-gel (Poerwadi et al., 2020), screening and drying a composite solution to form a rougher result (Rochardjo et al., 2019), or spin coating followed by direct immersion in distilled water of polyethersulfone (Prihandana et al., 2015). With electrospinning, PVA fibers can be produced with a diameter ranging from ten to hundreds of nanometers (Rezaei et al., 2016).

In the electrospinning process, a high voltage is applied to the polymer solution through the tip of one or more syringe needles. The applied electric field then breaks the droplet's surface tension, and a jet of polymer travels through it toward the grounded collector, which placed at a known distance from the needle tip (Sousa et al., 2015). The quality of the nanofibers depends on some electrospinning parameters, such as the voltage and distance. Several studies have been carried out on the production of nanofiber membranes using PVA and electrospinning methods, e.g., Jeong et al., (2007); Sousa et al., (2015); Rezaei et al., (2016); and Hulupi and Haryadi (2019). However, the strengthening the PVA with ramie CNCs is rarely found. This study was carried out to determine the electrospinning parameters and effects of CNC contents on a ramie CNC-reinforced PVA membrane. The resulting membrane was then evaluated further to ensure its applicability in nanofiltration membrane.

\section{Methods}

\subsection{Extraction and Production of Cellulose Nanocrystal (CNC)}

Figure 1 shows that the extraction and production of CNC are carried out in two steps, namely purification and acid hydrolysis. Purification starts with cutting dry ramie fiber to a length of $\pm 3 \mathrm{~mm}$ and dewaxing it using ethanol and toluene (2:1) (v/v) (ASTM D-1107, 2001) with a soxhlet apparatus for six hours. Alkali treatment was carried out in a $2 \% \mathrm{NaOH}$ solution for two hours at a temperature of $90^{\circ} \mathrm{C}$ with a fiber and $\mathrm{NaOH}$ solution ratio of 1:2 (w/v) (Silvério et al., 2013; Darmanto et al., 2017). In addition, the bleaching process, consisting of $3 \% \mathrm{H}_{2} \mathrm{O}_{2}$ (50\% purity) and $0.2 \% \mathrm{NaOH}$ (99\% purity), was carried out at $60^{\circ} \mathrm{C}$ with pH 10 for one hour at a fiber-to-bleach ratio of 1:100 (w/v) (Silvério et al., 2013; Yudhanto et al., 2018; Yudha et al., 2018). CNC production employs the acid hydrolysis of sulfuric acid $\left(\mathrm{H}_{2} \mathrm{SO}_{4}\right)$ due to its ability to produce hydroxyl groups of sulfate ester $\left(-\mathrm{OSO}_{3}\right)$. This causes the formation of negative electrostatic coatings covering the nanocrystal and encourages CNC dispersion in water due to repulsion between the nanoparticles, thereby making it stable in water. Acid hydrolysis uses $35 \% \mathrm{M} \mathrm{H}_{2} \mathrm{SO}_{4}\left(96 \%\right.$ purity) at $45^{\circ} \mathrm{C}$ for 60 minutes compared to a ramie fiber and acid solution ratio of 1:20 (w/v). Furthermore, 
approximately $200 \mathrm{~mL}$ of hydrolysis solution was placed in cold distilled water to stop the acid reaction via a centrifuge apparatus (4000 rpm rotation) used to neutralize the fiber for 10 minutes. The CNC ramie fiber from the acid hydrolysis process was further treated with ultrasonic sound, since the cavitation process of ultrasonic sound is effective in uniformly opening the cellulose structure. The CNC was ultrasonicated with $40 \%$ of the ultrasonic apparatus power ( $300 \mathrm{~W}$ ) to produce $20-25 \mathrm{kHz}$ ultrasonic sound with an ultrasonic probe apparatus of $6 \mathrm{~mm}$. Finally, it was further ultrasonicated for an hour under an ice bath. For a more detailed fabrication method, see Fatkhurrohman (2019).

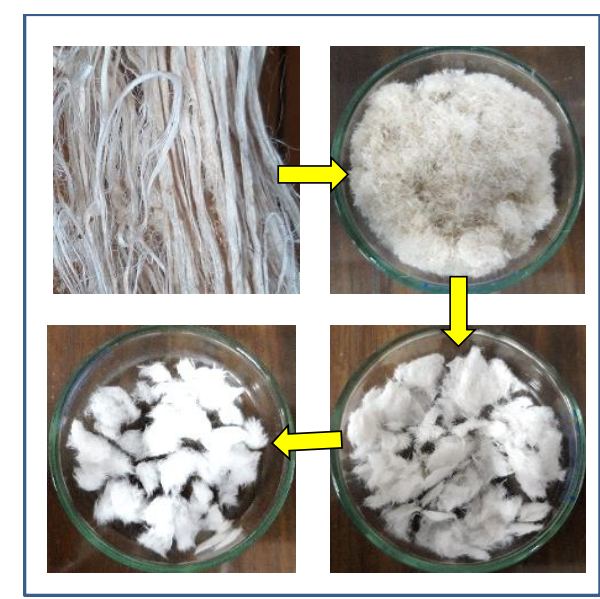

Purification

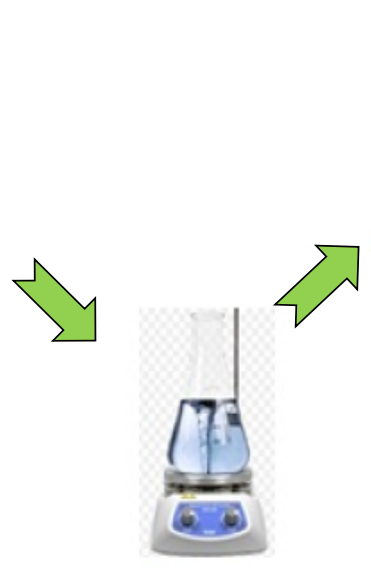

Acid hydrolysis

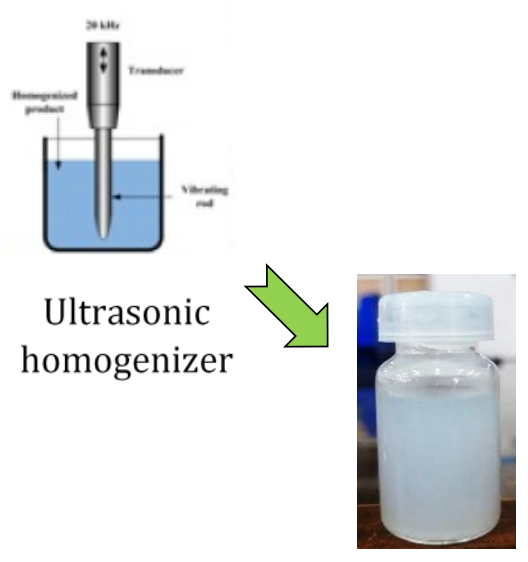

CNC ramie fiber

Figure 1 Extraction and production of CNC ramie fiber procedure

\subsection{Preparation of the Electrospinning Solution}

The solution consisting of $10 \%$ PVA in $100 \mathrm{~mL}$ distilled water $(\mathrm{w} / \mathrm{v})$ was heated and stirred with a magnetic stirrer at $85^{\circ} \mathrm{C}$ for two hours (Hulupi and Haryadi, 2019). This was followed by adding the CNC ramie fiber to the PVA solution with varying concentrations $(0$, $1,3,5$, and $7.5 \%$ ). The solution was stirred and heated using a magnetic stirrer at $40^{\circ} \mathrm{C}$ for an hour to obtain a homogenous CNC and PVA solution. In the next stage, the solution was allowed to stand for an hour to remove air bubbles trapped in the solution. Furthermore, the solution was ultrasonicated for five minutes to ensure it was completely mixed. Finally, it was stabilized for one hour before the electrospinning process. Figure 2 shows the electrospinning solution for each CNC content.

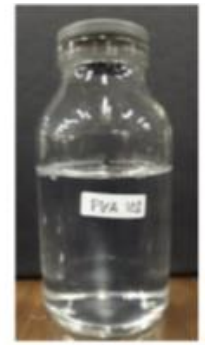

(a)

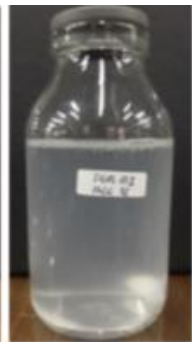

(b)

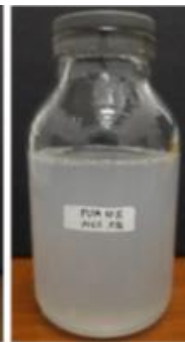

(c)

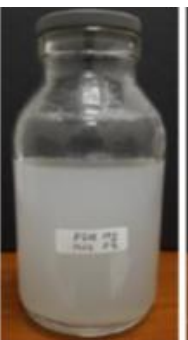

(d)

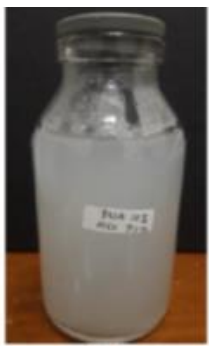

(e)

Figure 2 The electrospinning solution: (a) CNC/PVA 0/; (b) CNC/PVA 1/99; (c) CNC/PVA 3/97; (d) CNC/PVA 5/95; (e) CNC/PVA 7.5/92.5 (mL)

\subsection{Electrospinning Procedure}

Before carrying out the electrospinning process, the room needs to be sterilized from dust or other impurities that can stick to the nanofiber membrane. First, electrospinning 
was conducted on a solution without a $\mathrm{CNC}$ ramie fiber $(0 \%)$ at room temperature. A series of trial and error tests were also carried out with an applied voltage in the range of 10-15 $\mathrm{kV}$ and a membrane nanofiber collector distance from $9-15 \mathrm{~cm}$. The result showed that the conditions for obtaining bead-free CNC ramie fiber/PVA nanofibers were found at $15 \mathrm{kV}$, a flow rate $0.5 \mathrm{~mL} / \mathrm{h}$, and a distance collector of $12 \mathrm{~cm}$. The next step involved electrospinning the solutions containing the CNC ramie fiber, as shown in Table 1 . Positive and negative electrodes of high voltage were connected to a needle with a blunt tip and an aluminum foil collector.

Table 1 Composition of electrospinning solution

\begin{tabular}{ccc}
\hline Solutions & $\begin{array}{c}\text { CNC ramie fiber } \\
\text { concentration (\%) }\end{array}$ & $\begin{array}{c}\text { Proportion of CNC ramie } \\
\text { fiber/PVA solution (mL) }\end{array}$ \\
\hline PVA & 0 & $0 / 100$ \\
CNC/PVA & 1 & $1 / 99$ \\
CNC/PVA & 3 & $3 / 97$ \\
CNC/PVA & 5 & $5 / 95$ \\
CNC/PVA & 7.5 & $7.5 / 92.5$ \\
\hline
\end{tabular}

\subsection{Measurement and Characterization}

X-ray diffraction (XRD) was used to study the bleaching, hydrolysis, and ultrasonic alkaline treatment process, with the crystallinity index determined from the XRD graph pattern. The Rigaku Miniflex 600 Benchtop model was used to determine the radiation of $\mathrm{Cu} \mathrm{K \alpha}(\lambda=0.154 \AA \bar{s})$ at the operating voltage and current of $40 \mathrm{kV}$ and $20 \mathrm{~mA}$. Scanning started from an angle of $2 \theta=5^{\circ}$ to $50^{\circ}$, and the crystallinity index (CrI) was determined using the Segal method (Segal et al., 1959), as shown in Equation 1.

$$
\operatorname{CrI}=\frac{\left(I_{002}-I_{a m}\right)}{I_{002}} \times 100 \%
$$

Scanning electron microscopy (SEM) is used to observe the membrane's morphology, which is used as a parameter to determine the success of the fabrication process. Samples need to be dry and coated with gold $(\mathrm{Au})$ to be observed with SEM model JEOL-JSM 6510LA using voltages from $5 \mathrm{kV}$ to $15 \mathrm{kV}$.

Furthermore, the membrane nanofibers' tensile strength and the elongation-at-break were examined using a universal tensile test machine (UTM). ASTM D-638 type V (2020) was used to test each sample, with analysis conducted at a stretching rate of $10 \mathrm{~mm} \mathrm{~min}-1$. The standard was used due to limitations in fulfilling the specimen length, as suggested in ASTM D882. The thickness of the nanofiber samples was measured using an electronic digital micrometer before examining and analyzing four replicates for each sample.

Thermogravimetric analysis (TGA) characterization is used to observe a sample's weight changes due to chemical or physical changes in a material as a function of temperature and time. For this purpose, samples were heated from $27^{\circ} \mathrm{C}$ to $600^{\circ} \mathrm{C}$ at $10^{\circ} \mathrm{C} / \mathrm{min}$ in a nitrogen environment with a $30 \mathrm{~mL} / \mathrm{min}$ flow rate. Phase changes were also analyzed using differential scanning calorimetry (DSC), which functions by comparing the temperature change with the reference material.

\section{Results and Discussion}

\subsection{Morphology of $C N C$}

Using Image software for the CNC TEM image, it was discovered that the diameter of the $\mathrm{CNC}$ fibers ranged from $2 \mathrm{~nm}$ to $15 \mathrm{~nm}$, with an average of $8 \mathrm{~nm}$. The length ranged from 
50 to $250 \mathrm{~nm}$, with an average of $153 \mathrm{~nm}$ and the crystalline index based on the XRD image calculated to be 90.5 .

\subsection{Electrospinning Process of Membrane Nanofiber}

A CNC ramie fiber-reinforced PVA membrane with varying CNC contents was fabricated with several experimental trials carried out using varying voltages between $10-$ $15 \mathrm{kV}$ to determine the appropriate voltage and obtain uniform dimensions of the nanofibers. When the voltage was set to $10-13 \mathrm{kV}$, droplets were observed at the needle tip, thereby forming an imperfect nanofiber. At CNC contents from 0 to 5\%, nanofibers of 14-15 kV were perfectly formed without droplets. However, at a higher CNC concentration of $7.5 \%$, the droplets resumed, and the nanofiber fell before it reached the collector due to the large CNC content. Furthermore, the distance between the needle tips and the collector was also experimentally determined. Droplets were also observed at a distance of $11 \mathrm{~cm}$ (starting at $10 \mathrm{~cm}$ ), while, at $12 \mathrm{~cm}$, they disappeared, and the nanofiber membrane was perfectly formed. However, this did not apply to nanofiber membranes with a $7.5 \%$ CNC concentration, which still exhibited non-severe droplets. This could be related to the charge repulsion among the CNC ramie fiber polyanions, which can cause a lack of adequate chain entanglements in the CNC ramie fiber (Rezaei et al., 2016). It can be concluded that the voltage and distance of the collector from the tip of the needle has a significant impact on the quality of the nanofiber membrane produced.

\subsection{Morphology of Membrane Nanofiber}

The produced nanofiber membranes were removed from aluminum foil and tested for mechanical property characterization. Figure 3 shows that there is visually no significant difference between the membranes, because, when it dried, the PVA tended to be white, and the NCC of the ramie fiber was used as reinforcement. The amount of CNC ramie reinforced on the PVA fiber in the membranes did not differ greatly from one specimen to another due to the similarities in the electrospinning time.

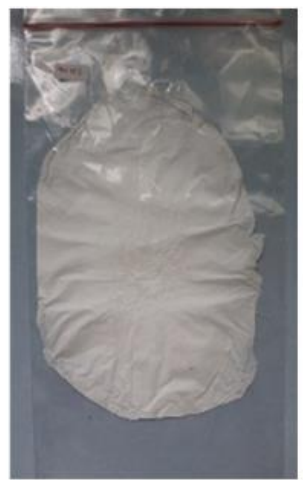

(a)

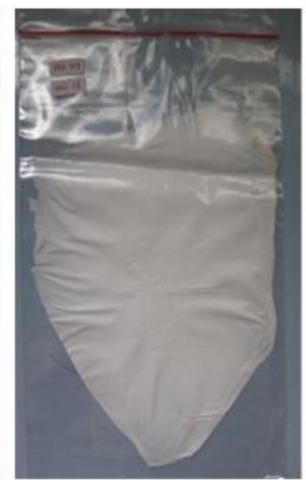

(b)

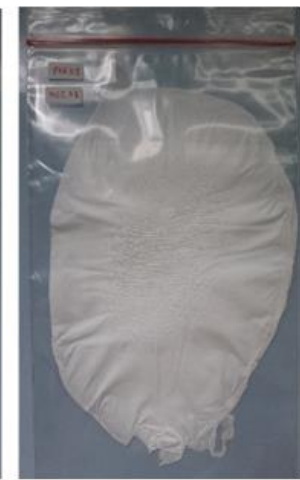

(c)

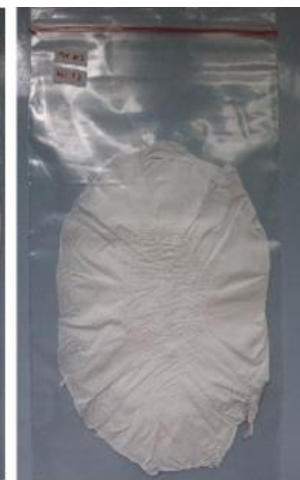

(d)

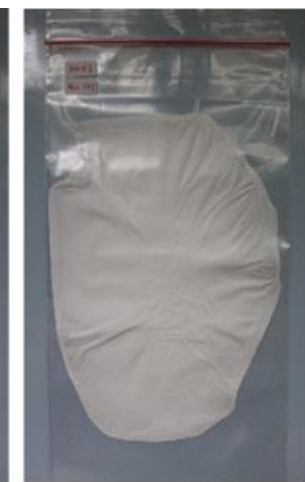

(e)

Figure 3 The resulted membrane: (a) CNC/PVA 0/100; (b) CNC/PVA 1/99; (c) CNC/PVA 3/97; (d) CNC/PVA 5/95; (e) CNC/PVA 7.5/92.5 (mL)

Figure 4 shows the results of the SEM observations of the membranes with $5 \%$ CNC content. It appears that the resulting membrane has a clean and uniform fiber diameter without defects. This also was observed with lower CNC contents via further SEM image analysis to determine the fiber diameter and pore size distributions, which were then plotted on a histogram, using Image J software. The calculation using Image J software shows that the average fiber and pore equivalent diameters are $147.15 \mathrm{~nm}$ and $11.8 \mathrm{~nm}$, respectively, as depicted in Figure 5. Such a pore size can be used in nano filtration processes. Figure 6 shows the various defects associated with a CNC concentration of 7.5\% 
on the nanofiber membrane in the form of beads and other anomalies due to the possibility of the $\mathrm{CNC}$ ramie fiber being agglomerated during the electrospinning process. Therefore, when it emerges from the needle's tip, the nanofiber membrane is large in dimension. Other defects also occur in the form of droplets on the nanofiber membrane, which occur due to the increased viscosity of the electrospinning solution due to the high CNC ramie fiber content. These results are identical to those in research conducted by Rezaei et al. (2016), who made nanofibers from almond gum/PV.

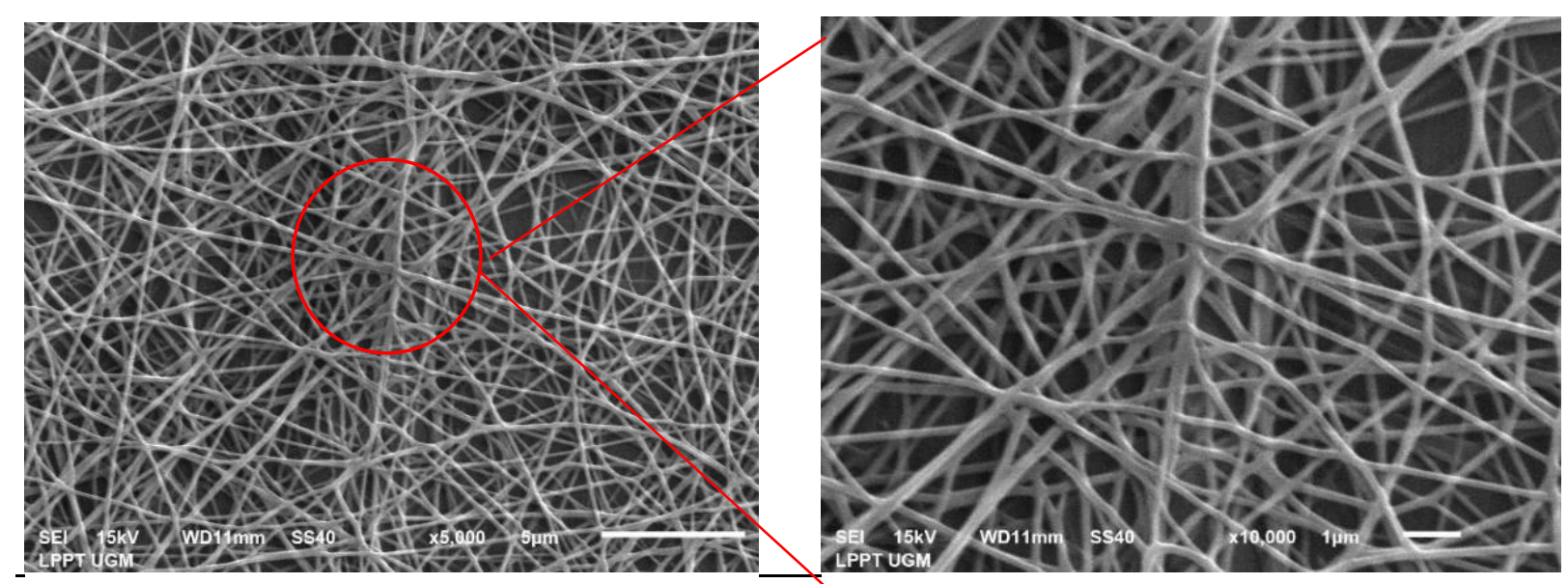

Figure 4 SEM image of membrane nanofiber with CNC 5\%
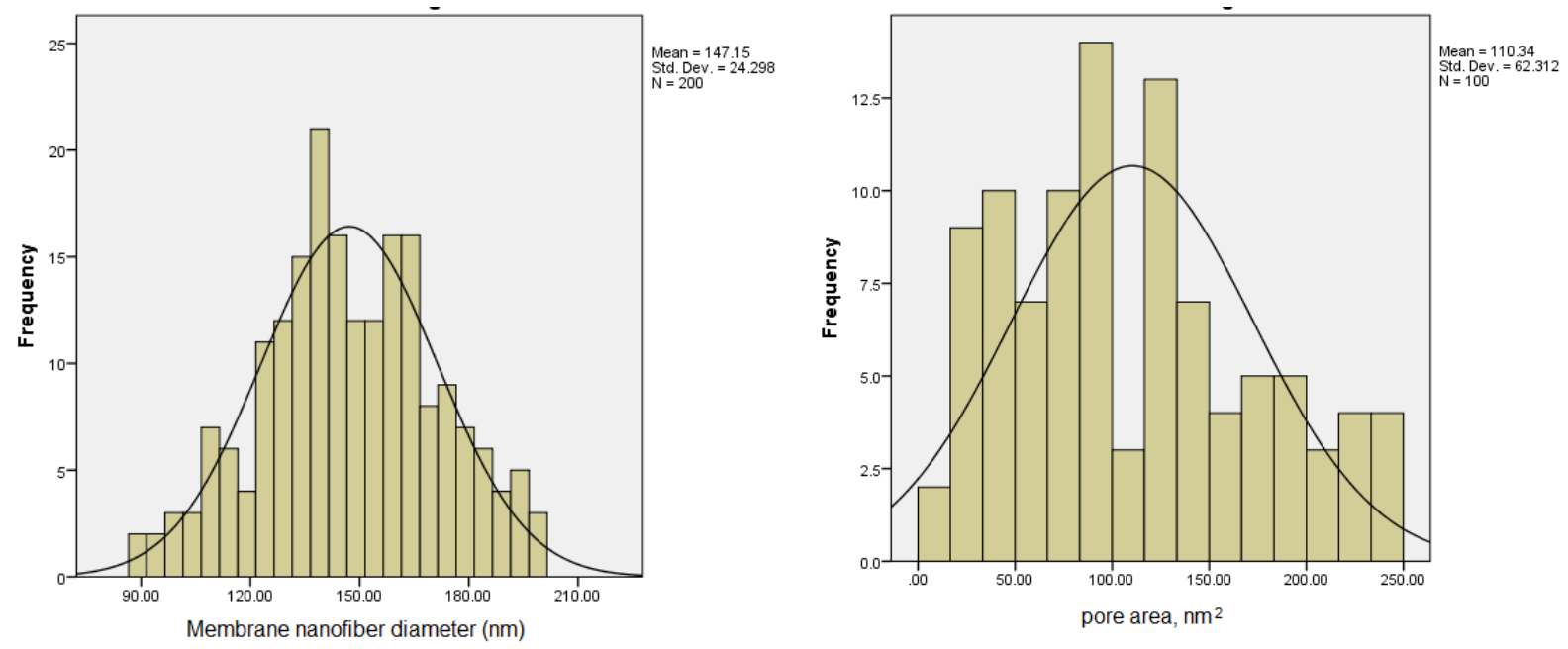

Figure 5 Fiber diameter and porosity area distribution of CNC 5\%

Based on these experiments, it can be concluded that the CNC content impacts the nanofiber membrane produced. At CNC content less than $5 \%$, the electrospinning process functions properly; however, the nanofiber membrane using the CNC ramie content of $7.5 \%$, exhibit an average larger diameter and pores. This occurrence can be attributed to an increase in the weight or viscosity of the solution, which make the force of the electric field unable to push the polymer solution, thereby resulting in an agglomeration of CNC ramie fibers in the electrospinning solutions, as shown in Figure 6.

Scanning Electron Microscope-Energy Dispersive X-Ray (SEM-EDX) testing was carried out on the nanofiber membrane to confirm the produced nanocomposite membrane's composition value. Specifically, SEM-EDX was conducted at two points of observation, as shown in Figure 7. 


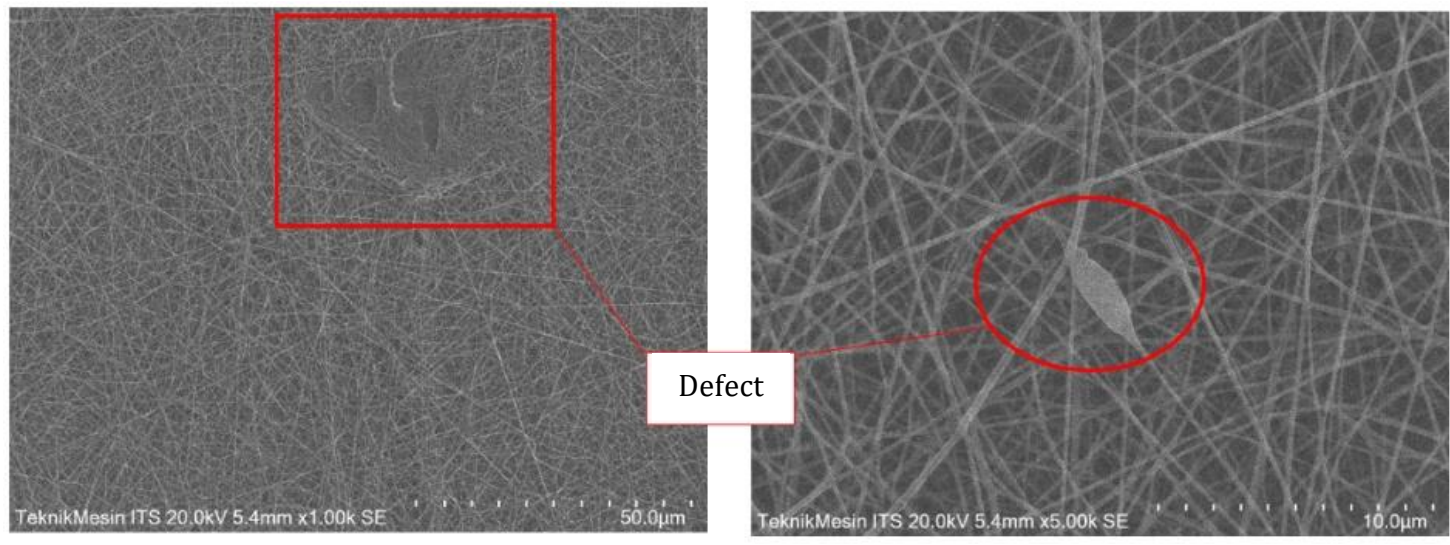

Figure 6 SEM image of defect in membrane nanofiber with CNC 7.5\%

The spectrum in Figure 7a showed that $\mathrm{Al}$ is the highest element (shown by the dark point) weighing 83\%. This is because the dark region of the SEM image indicates the media attached to the aluminum foil. Spectrum in Figure $7 \mathrm{~b}$ was spotted on the fiber, which shows that element $\mathrm{C}$ was the highest weighted at $42 \%$, followed by 0 , which weighed $24 \%$. This is also in accordance with the composition of the nanofiber membrane produced in this study.
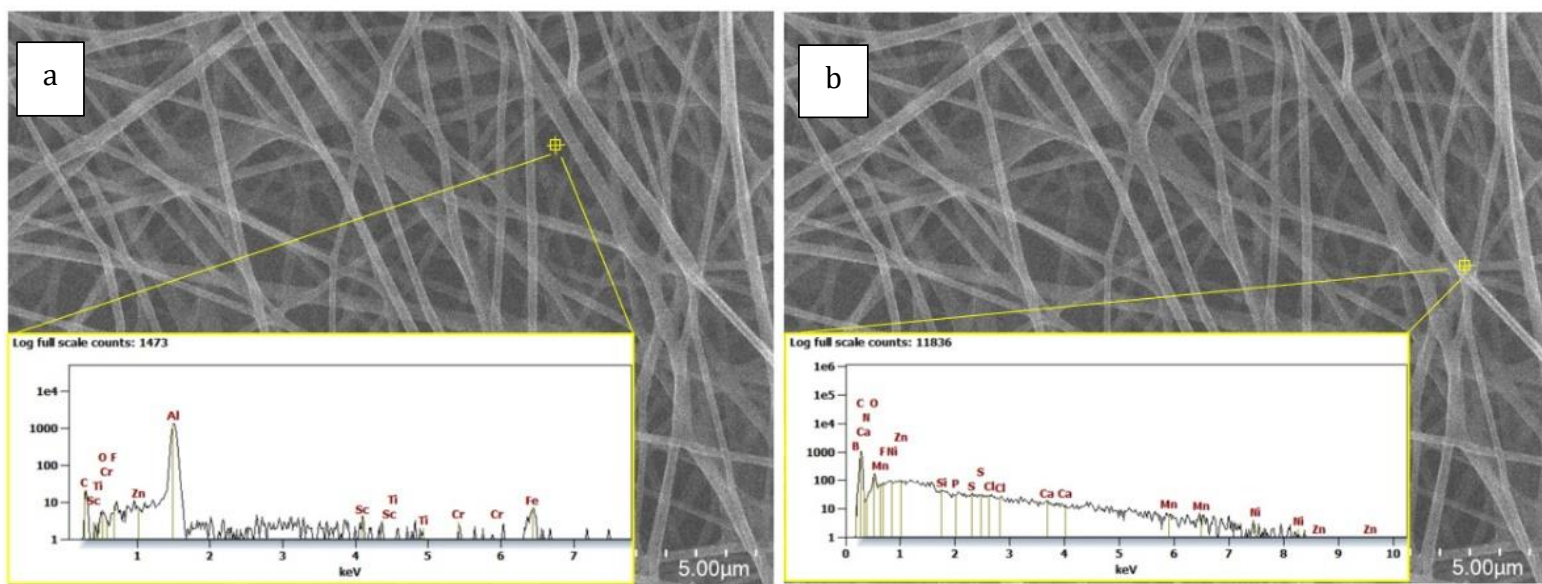

Figure 7 SEM-EDX membrane nanofiber

\subsection{Mechanical Properties of Membrane Nanofiber}

A membrane morphology with a higher CNC content affected the membrane's mechanical properties. As shown in Figure 8a, the addition of CNC content increases the membrane's tensile strength. The highest tensile strength was found with a $5 \%(\mathrm{v} / \mathrm{v}) \mathrm{CNC}$ ramie fiber addition, with an average of $34.23 \mathrm{MPa}$, which was twice that without CNC. However, the addition of $7.5 \%$ (v/v) CNC ramie decreased the average tensile strength to 16.33 Mpa. Therefore, it can be concluded that the addition of CNC ramie fiber has a positive impact on the tensile strength of nanofiber membranes-with a limit of $5 \%(\mathrm{v} / \mathrm{v})$. The increase in the nanofiber membranes tensile strength is due to the increasing amount of the reinforcing elements. The defects on the membrane with $7.5 \% \mathrm{CNC}$ decrease the tensile strength. Although it does not have an adverse effect on the tensile strength, the phenomena also happen to the elongation to break, as shown in Figure $8 \mathrm{~b}$. 


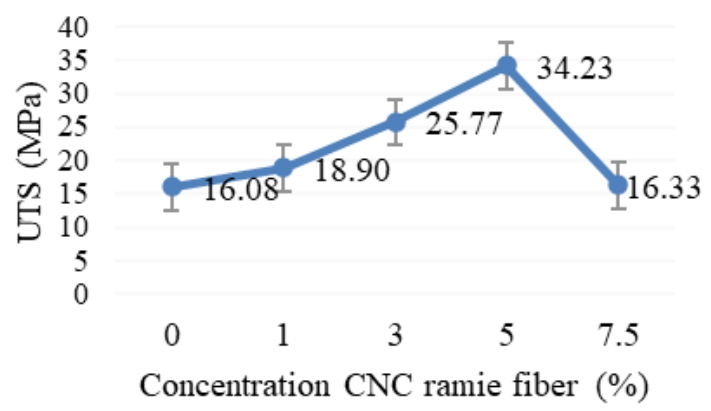

(a)

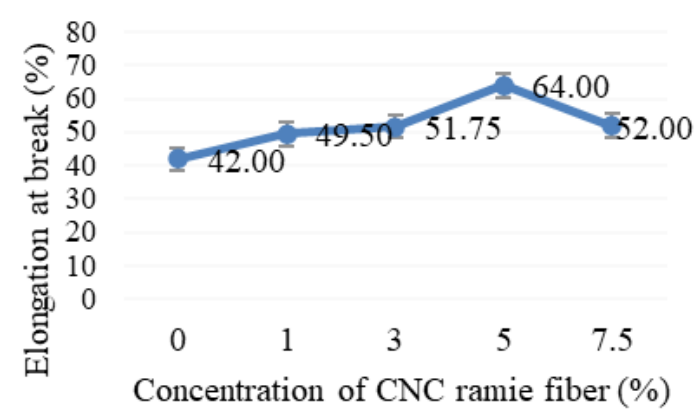

(b)

Figure 8 Tensile strength (a) and elongation at break (b)

\subsection{Thermal Analysis of Membrane Nanofiber}

Figures 9a and 9b show the TGA and DSC test curves from the CNC ramie fiber and nanofiber membrane, which are used to determine their thermal stability. The two curves show the weight loss in each sample by approximately $10 \%$ in the temperature range of $30^{\circ} \mathrm{C}-100^{\circ} \mathrm{C}$ due to the evaporation of water in each sample. The nanofiber membranes experienced a $15 \%$ weight reduction in the temperature range of $110^{\circ} \mathrm{C}-250^{\circ} \mathrm{C}$, which indicates that the CNC ramie fiber was degraded from the PVA. Meanwhile, a weight reduction of approximately $70 \%$ occurred in the temperature range of $270^{\circ} \mathrm{C}-370^{\circ} \mathrm{C}$, which indicates that the PVA in the nanofiber membrane was degraded. Ramie fiber CNC has a better thermal degradation temperature when compared to the nanofiber membranes, since its curve is above the thermal curve.

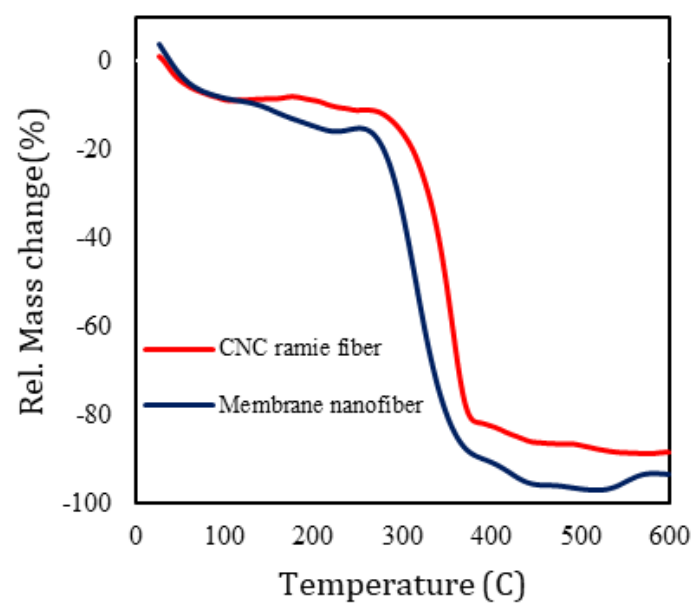

(a)

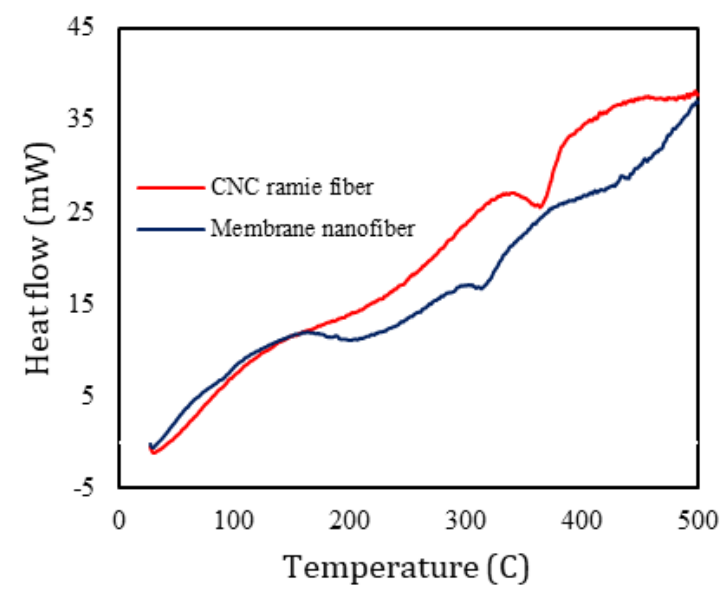

(b)

Figure 9 TGA (a) and DSC (b) membrane nanofiber and CNC ramie fiber

In addition, the DSC test was used to support the TGA analysis, and the results are shown in Figure 9b. The DSC curves of both samples showed an endothermic peak in the temperature range of $300^{\circ} \mathrm{C}-400^{\circ} \mathrm{C}$, which corresponded to a decrease in weight on the TGA graph. This also showed that the endothermic peak on the DSC curve indicated a decomposition process in the material. Therefore, the DSC test results confirmed that the reaction of the two samples is an endothermic reaction, which indicates the sample absorbs heat with a decomposition or evaporation reaction. In $\mathrm{CNC}$, ramie fibers occur in the temperature range of $320^{\circ} \mathrm{C}-370^{\circ} \mathrm{C}$. Meanwhile, in the nanofiber membrane, it is $300^{\circ} \mathrm{C}-$ $340^{\circ} \mathrm{C}$, with a thermal resistance of $300^{\circ} \mathrm{C}-340^{\circ} \mathrm{C}$. Therefore, it is still very safe when used as a filter at room temperature. 


\section{Conclusions}

The fabrication of composite nanofiber membranes from CNC ramie fiber and PVA has been successfully conducted. Due to the average pore size of $11.8 \mathrm{~nm}$ in nanofiber membranes, it can be used as a nano-filtration process in general. The addition of 5\% CNC ramie fiber $(\mathrm{v} / \mathrm{v})$ has a positive impact on the tensile strength and elongation of the nanofiber membrane. The membrane was produced perfectly with a voltage of $15 \mathrm{kV}$ and a distance between the tip and collector of $12 \mathrm{~cm}$. However, at higher CNC contents, it needs further investigation, since the resulting membrane was not good, as shown by the existence of defects on the membrane that resulted in lower mechanical properties. The thermal resistance of the nanofiber membrane is in the temperature range of $300^{\circ} \mathrm{C}-340^{\circ} \mathrm{C}$; therefore, the membrane is safe when used at room temperature and higher.

\section{Acknowledgements}

The authors would like to acknowledge the Department of Mechanical and Industrial Engineering Universitas Gadjah Mada for providing research equipment and supporting the publication.

\section{References}

ASTM D638-14 type V:2020. Standard Test Method for Tensile Properties of Plastics; ASTM International: West Conshohocken, PA, USA, 2020

Darmanto, S., Rochardjo, H.S.B., Jamasri, Widyorini, R., 2017. Effects of Alkali and Steaming on Mechanical Properties of Snake Fruit (Salacca) Fiber In: AIP Conference Proceedings, 1788 (January)

Fatkhurrohman, 2019. Fabrication And Characterization Of Nanocomposite Membrane From Nanocellulose Ramie Fiber With PVA Matrix, Master Thesis, Graduate School of Mechanical Engineering, Universitas Gadjah Mada, Yogyakarta

Heinze, T., El Seoud, O.A., Koschella, A., 2018. Production and Characteristics of Cellulose from Different Sources. Cellulose Derivatives, Springer Series on Polymer and Composite Materials. Springer, Cham., pp. 1-38

Helmiyati., Anggraini, Y., 2019. Nanocomposites Comprising Cellulose and Nanomagnetite as Heterogeneous Catalysts for the Synthesis of Biodiesel from Oleic Acid. International Journal of Technology, Volume 10(4), pp. 798-807

Hulupi, M., Haryadi, H., 2019. Synthesis and Characterization of Electrospinning PVA Nanofiber-Crosslinked by Glutaraldehyde. Materials Today: Proceedings, Volume 13(1), pp. 199-204

Jeong, J.S., Moon, J.S., Jeon, S.Y., Park, J.H., Alegaonkar, P.S., Yoo, J.B., 2007. Mechanical Properties of Electrospun PVA/MWNTs Composite Nanofibers. Thin Solid Films, Volume 515(12), pp. 5136-5141

Kim, J.H., Shim, B., Kim, H.S., Lee, Y.J., Min, S.K., Jang, D., Abas, Z., Kim, J., 2015. Review of Nanocellulose for Sustainable Future Materials. International Journal of Precision Engineering and Manufacturing - Green Technology, Volume 2(2), pp. 197-213

Poerwadi, B., Kartikowati, C.W., Oktavian, R., Novaresa, O., 2020. Manufacture of a Hydrophobic Silica Nanoparticle Composite Membrane for Oil-Water Emulsion Separation. International Journal of Technology, Volume 11(2), pp. 364-373

Prihandana, G.S., Sriani, T., Mahardika, M., 2015. Review of Surface Modification of Nanoporous Polyethersulfone Membrane as a Dialysis Membrane. International Journal of Technology, Volume 6(6), pp. 1025-1030

Rezaei, A., Tavanai, H., Nasirpour, A., 2016. Fabrication of Electrospun Almond Gum/PVA 
Nanofibers as a Thermostable Delivery System for Vanillin. International Journal of Biological Macromolecules, Volume 91, pp. 536-543

Rochardjo, H.S.B., Jamasri, J., Yudhanto, F., 2019. Extraction of Natural Fibers by High-Speed Blender to Produce Cellulose Sheet Composite. International Review of Mechanical Engineering, Volume 13(12), pp. 691-699

Sanders, J.E., Han, Y., Rushing, T.S., Gardner, D.J., 2019. Electrospinning of Cellulose Nanocrystal-Filled Poly (Vinyl alcohol) Solutions: Material Property Assessment. Nanomaterials, Volume 9(5), pp. 1-16

Segal, L., Creely, J.J., Martin, A.E., Conrad, C.M., 1959. An Empirical Method for Estimating the Degree of Crystallinity of Native Cellulose Using the X-Ray Diffractometer. Textile Research Journal, Volume 29(10), pp. 786-794

Silvério, H.A., Flauzino Neto, W.P., Dantas, N.O., Pasquini, D., 2013. Extraction and Characterization of Cellulose Nanocrystals from Corncob for Application as Reinforcing Agent in Nanocomposites. Industrial Crops and Products, Volume 44, pp. 427-436

Sousa, A.M.M., Souza, H.K.S., Uknalis, J., Liu, S.C., Gonçalves, M.P., Liu, L., 2015. Electrospinning of Agar/PVA Aqueous Solutions and its Relation with Rheological Properties. Carbohydrate Polymers, Volume 115, pp. 348-355

Yudha, V., Rochardjo, H.S.B., Jamasri, J., Widyorini, R., Yudhanto, F., Darmanto, S., 2018. Isolation of Cellulose from Salacca Midrib Fibers by Chemical Treatments. IOP Conference Series: Materials Science and Engineering, Volume 434(1), p. 1-5

Yudhanto, F., Jamasri, Rochardjo, H.S.B., 2018. Physical and Thermal Properties of Cellulose Nanofibers (CNF) Extracted from Agave Cantala Fibers Using Chemical-Ultrasonic Treatment. International Review of Mechanical Engineering, Volume 12(7), pp. 597603 